\title{
STRUKTUR FRASA VERBAL BAHASA BANJAR HULU: TINJAUAN BENTUK GRAMATIKAL
}

\author{
Asnawi \\ Universitas Islam Riau, Pekanbaru, Indonesia \\ asnawi@edu.uir.ac.id
}

\begin{abstract}
The basis of the emergence of this research is the lack of observers or language researchers who will arouse the local language khasanah, namely Banjar Hulu language. Upstream Banjar Language is a language used by the people of Suhada Village Enok District Indragiri Hilir Regency Riau. The Banjar Hulu language is used as the majority language used by the people of Indragiri Hilir Regency Riau. However, due to the flow of modernization and assimilation will threaten the extinction and contamination of the Banjar Hulu language. Therefore, this research is expected to maintain and maintain the authenticity of Banjar Hulu language, so it is necessary to do research. This study focuses on the structure of verb phrases. With related issues about the shape or structure of the verb phrase. The purpose of the study is to describe in detail the structure of the Banjar Hulu language verb phrase. This research is a field research with qualitative type. This research was conducted in Suhada Village, Enok Sub-district, Indragiri Hilir Regency, Riau with research time for six months. The method used to collect data is by the technique of referring libat ably. The data of this research is phrase construction that comes from the speech of research informant. Data analyzing is done by technique of reduction, disply, and conclusion data. The results showed that there are various verbal phrases. This kevariasian found verbal language phrases Banjar Hulu language based on the class of formers and verbal phrase forming function, namely coordinative verbal phrases, modifikatif, and apositif. The results of this study are the first structure of verbal phrases based on the word class; (v) Verbal Phrase $\{\mathrm{V}+\mathrm{Ajk}\}$, (c) Verbal Phrases $\{\mathrm{Adv}+\mathrm{V}\}$, (d) Verbal Phrases $\{\mathrm{V}+$ Prepositions $\}$, (e) ) Verbal Phrases $\{\mathrm{V}$; (ba- $+\mathrm{N})+$ pronomina $\}$, (f) Verbal Phrases $\{\mathrm{V}$; (b) $+\mathrm{A}\}$, (g) Verbal Phrases $\{\mathrm{V} ;(\mathrm{b}++\mathrm{N})+\mathrm{N}\}$. The two structures of the verbal phrase are based on the function of the constituent elements, which include (a) Coordinative Verbal Phrases, (b) Modifikattive Verb Phrases, (c) Apositive Verb Phrases.
\end{abstract}

Keywords: verbal phrase structure, Banjar Hulu language, grammatical

\begin{abstract}
ABSTRAK
Dasar munculnya penelitian ini adalah kurangnya pemerhati atau peneliti bahasa yang akan menggugah khasanah bahasa daerah, yakni bahasa Banjar Hulu. Bahasa Banjar Hulu merupakan bahasa yang dipergunakan oleh masyarakat Desa Suhada Kecamatan Enok Kabupaten Indragiri Hilir Riau. Bahasa Banjar Hulu dijadikan sebagai bahasa mayoritas yang digunakan oleh masyarakat Kabupaten Indragiri Hilir Riau. Namun, akibat adanya arus modernisasi dan asimilasi akan mengancam kepunahan dan kontaminasi bahasa Banjar Hulu. Oleh sebab itu, penelitian ini diharapkan untuk mempertahankan dan menjaga keaslian akan bahasa Banjar Hulu, sehingga perlu dilakukan penelitian. Penelitian ini berfokus pada struktur frasa verba. Dengan masalah terkait tentang bentuk atau struktur pembentuk frasa verba. Tujuan penelaahan adalah untuk mendeskripsikan secara rinci tentang struktur frasa verba bahasa Banjar Hulu. Penelitian ini merupakan penelitian lapangan dengan jenis kualitatif. Penelitian ini dilakukan di Desa Suhada Kecamatan Enok Kabupaten Indragiri Hilir Riau dengan waktu penelitian selama enam bulan. Metode yang digunakan untuk mengumpulkan data adalah dengan teknik simak libat cakap. Data penelitian ini adalah konstruksi frasa yang bersumber dari tuturan informan penelitian. Penganalisisan data dilakukan dengan teknik reduction, disply, dan conclusion data. Hasil penelitian menunjukan bahwa terdapat frasa verbal yang bervariasi. Kevariasian ini yakni ditemukan frasa verbal bahasa Banjar Hulu berdasarkan kelas kata pembentuknya dan fungsi pembentuk frasa verbal, yakni frasa verbal koordinatif, modifikatif, dan apositif. Hasil penelitian ini
\end{abstract}


adalah pertama struktur frasa verbal berdasarkan kelas katanya; (a) Frasa Verbal $\{\mathrm{V}+(\mathrm{V} ; \operatorname{trn})\}$, (b) Frasa Verbal $\{\mathrm{V}+\mathrm{Ajk}\}$, (c) Frasa Verbal $\{\mathrm{Adv}+\mathrm{V}\}$, (d) Frasa Verbal $\{\mathrm{V}+$ Preposisi $\}$, (e) Frasa Verbal $\{\mathrm{V} ;($ ba- $+\mathrm{N})+$ pronomina $\}$, (f) Frasa Verbal $\{\mathrm{V}$; (ba- N) $+\mathrm{A}\}$, (g) Frasa Verbal $\{\mathrm{V}$;(ba-kan $+\mathrm{N})+\mathrm{N}\}$. Kedua struktur frasa verbal berdasarkan fungsi unsur pembentuk, yakni meliputi (a) Frasa Verbal Koordinatif, (b) Frasa Verba Modifikatif, (c) Frasa Verba Apositif.

\section{Kata Kunci: struktur frasa verbal, bahasa Banjar Hulu, gramatikal}

\section{PENDAHULUAN}

Frasa merupakan gabungan dari beberapa kata yang memiliki satu peran fungsi. Frasa biasanya bersifat nonpredikatif. Frasa adalah gabungan dua kata atau lebih yang bersifat nonpredikatif. Hal tersebut diperkuat oleh pendapat Ramlan (2005:138) "Frasa adalah satuan gramatik yang terdiri daru dua kata atau lebih yang tidak melampai batas fungsi unsur klausa". Berdasarkan persamaan distribusi dengan golongan atau kategori kata.

Frasa dapat digolongkan menjadi empat golongan, yaitu frasa nominal, frasa verbal. Frasa bilangan, dan frasa keterangan. Frasa nominal memiliki distribusi yang sama dengan kata golongan nominal, frasa verbal mempunyai distribusi yang sama dengann kata verbal, frasa bilangan mempunyai distribusi yang sama dengan kata bilangan, dan frasa keterangan mempunyai distribusi yang sama dengan kata keterangan. Di samping itu, ada frasa yang tidak memiliki persamaan distribusi dengan golongan kata, yaitu yang disebut frasa depan, sehingga seluruhnya terdapat lima golongan frasa, yaitu frasa nominal, frasa verbal, frasa bilangan, frasa keterangan, dan frasa depan ( Ramlan, 2005:145).

Frasa verbal atau frasa golongan $\mathrm{V}$ ialah frasa yang mempunyai distribusi yang sama dengan kata verbal" (Ramlan 2005:154). Dalam frasa verbal ini terdapat kata tambah (T), yang termasuk kata tambah yaitu kata akan, sudah, sering, dapat, sedang, baru, tidak, mungkin, sering tentu, pasti, belum, lagi, tengah, jarang, kerapkali, pernah, selalu, ingin, harus, wajib, perlu, bisa, sanggup, bersedia, mau, boleh, amat, sangat, terlalu, kurang, sekali,dan saja.

Hal tersebut juga berlaku dalam bahasa Banjar. Bahasa Banjar merupakan bahasa yang dipergunakan oleh masyarakat desa Suhada Kecamatan Enok Kabupaten Indragiri Hilir Riau (Asnawi, 2014:22). Bahasa Banjar terdiri atas bahasa Banjar Kuala
(BK) dan bahasa Banjar Hulu (BH). Setiap kelompok bahasa tersebut memiliki kawasan dan wilayah pemakaian yang cukup luas. Serta memiliki berbagai perbedaan sistem linguistik. Adanya dua dialek tersebut didasarkan pada pemakaian kosakata dan sistem bunyi vokal. Hapip (1975:v) dalam Suryadikara, (1981:2) "Memberikan informasi tentang dua dialek bahasa Banjar, yaitu bahasa Banjar Kuala dan bahasa Banjar Hulu. Adanya dua dialek itu didasarkan kepada perbedaan pemakaian kosa kata tertentu dan sistem bunyi vokal kedua dialek tadi."

Sementara itu, Hapip (1977:1) kembali mempertegas pernyataannya bahwa bahasa Banjar dibedakan menjadi dua dialek besar (1) dialek bahasa Banjar Kuala (disingkat BK), (2) dialek bahasa Banjar Hulu Sungai (disingkat BH). Jadi, bahasa Banjar terdiri atas bahasa Banjar Kuala (BK) dan bahasa Banjar Hulu (BH), hal tersebut terbentuk karena adanya perbedaan sistem linguistik dari kedua bahasa.

Kemudian, dari dua dialek besar bahasa Banjar itu, terdapat subdialek atau anak suku dari kedua variasi dialek tersebut. Hamer (1958) dalam Hapip (1977:1) mengatakan subdialek atau variasi tersebut dengan istilah "dialek lokal" sedangkan, Durasid dan Kawi dalam Suryadikara, (1981:2) menyebutnya "variasi subdialek". Selanjutnya, Hamer (1958) dalam Suryadikara, (1981:2) "Membagi bahasa Banjar Hulu atas dialek lokal Amuntai, Kuala, Tanjung, dan Kandangan." Mahdini (2003:1-2) memberikan informasi bahwa di Indragiri Hilir banyak terdapat subdialek bahasa Banjar Hulu. Dengan demikian, bahasa Banjar yang ada di daerah kabupaten Indragiri Hilir termasuk bahas Banjar Hulu (Asnawi, 2015:56). Alasan penulis memilih bahasa Banjar Hulu ialah karena bahasa Banjar Hulu banyak dijumpai di kabupaten Indragiri Hilir . Khususnya di Desa Suhada Kecamatan Enok. Penduduk Desa Suhada mayoritas menggunakan bahasa Banjar 
Hulu dalam kehidupan sehari-hari untuk berbagai kepentingan dan keperluan. Bahasa Banjar Hulu juga memiliki frasa verbal. Hal ini dapat dilihat pada contoh berikut ini.

\section{(1) Umanyak si Udin tu rahat manyambati urang nan tadi laluk. \\ Ibu Udian masih menceritakan orang yang baru saja lewat.}

\section{Subjek : umanya si udin \\ : FN (Frasa Nominal) Ibu Udin \\ Predikat: rahat manyambati \\ : FV (Frasa Verbal) \\ masih menceritakan \\ Objek : urang nan tadi laluk \\ : FN (Frasa Nominal) \\ orang yang baru saja lewat}

Berdasarkan frasa rahat manyambati dalam kalimat di atas mempunyai distribusi yang sama dengan kata manyambati. Kata manyambati termasuk golongan V. Oleh karena itu, frasa rahat manyambati juga termasuk golongan V. Kata rahat termasuk golongan kata tambah (t), sedangankan kata manyambati termasuk golongan V. Jadi, secara kategorial frasa tersebut terdiri dari rahat (t) sebagai atribut diikuti manyambati (verba) sebagai UP yang tergolong sebagai frasa verbal. Berdasarkan hal tersebut maka penulis tertarik untuk melakukan penelitian tentang bahasa Banjar Hulu pada aspek struktur frasa verbal bahasa Banjar Hulu; Tinjauan Bentuk Gramatikal.

Berdasarkan latar belakang yang telah dipaparkan, penelitian ini difokuskan hanya pada struktur frasa verbal. Alasan penulis menelaah struktur frasa verbal adalah jika ditinjau berdasarkan distribusinya, frasa verbal berdistribusi sama dengan verba. Selanjutnya terdapat kategori tambah dalam frasa verbal, misalnya dengan adanya kata tambah masih yang kehadirannya dapat diabaikan. Selanjutnya, penelaahan ini diarahkan untuk melihat bagimana bentuk-bentuk struktur frasa verbal berdasarkan tinjauan gramatikal dengan memanfaatkan kata tambahan yang mengikuti frasa verbal. Hal ini dilakukan sebagai wujud untuk mendokumentasikan khasanah bahasa Banjar Hulu (Asnawi, 2017:36). Berdasarkan hal tersebut, penulis merumuskan masalah dalam penelitian ini adalah sebagai beriku.
Bagaimanakah struktur frasa verbal bahasa Banjar Hulu berdasarkan tinjaun bentuk gramatikal? Berdasarkan masalah yang ada, maka penelitian ini adalah untuk memperoleh deskripsi tentang struktur frasa verbal bahasa Banjar Hulu berdasarkan tinjaun bentuk gramatikal. Ada pun tujuan dari penelitian ini adalah mendeskripsikan, mengelompokan bentuk-bentuk struktur frasa verbal bahasa Banjar Hulu berdasarkan tinjaun bentuk gramatikal di Desa Suhada Kecamatan Enok Kabupaten Indragiri Hilir Riau.

\section{METODOLOGI PENELITIAN}

Penelitian ini dilaksanakan di Desa Suhada Kecamatan Enok Kabupeten Indragiri Hilir Riau. Pendekatan yang digunakan dalam penelitian ini adalah pendekatan kualitatif karena penelitian ini bersifat mendeskripsikan struktur frasa verbal dalam bahasa Bahasa Banjar Hulu. Penelitian yang bersifat deskriptif menurut Arikunto lebih tepat apabila menggunakan pendekatan kualitatif. (Arikunto, 1993:209). Data dalam penelitian ini berupa satuan atau kontruksi kata yang berbentuk frasa verbal Bahasa banjar Hulu. Data yang diperoleh dalam penelitian ini berasal data informan yang mengungkapkan tentang struktur frasa verba bahasa bahasa Banjar Hulu. Sumber data tersebut meliputi segenap unsur yang terkait dalam penelitian iniyaitu tokoh masyarakat, tokoh agama, serta masyarakat sekitar desa Suhada Kecamatan Enok Kabupaten Indragiri Hilir. Data penelitian ini diperoleh dengan teknik pengumpulan data simak cakap (Sudaryanto, 1992:1-7 dan Mahsun, 2006:218-229). Data yang diperoleh perlu dilakukan pengabsahan data dengan menggunakan teknik triangulasi sumber (Moleong, 2010:330-331). Metode analisis data yang digunakan adalah metode agih (Sudaryanto, 1993:15).

\section{HASIL DAN PEMBAHASAN}

Berdasarkan penelaahan yang telah dilakukan, frasa verbal bahasa Banjar Hulu dapat ditelaah berdasarkan kelas kata pembentuknya. Frasa verbal berdasarkan kelas kata ditinjau dari bagaimana unsur pengisi frasa verbal. Unsur pengisi yang dimaksud ditinjau berdasarkan kategori atau kelas kata pembentuk frasa verbal bahasa Banjar Hulu. Berdasarkan kelas kata pembentuknya struktur frasa verbal 
memiliki struktur yang bervariasi. Lebih jelas

akan dipaparkan pada bagian berikut ini.

\section{a. Frasa Verbal $\{\mathbf{V}+(\mathbf{V}$;trn $)\}$}

Frasa verbal bahasa Banjar Hulu ditemukan struktur frasa verbal $\{\mathrm{V}+(\mathrm{V} ; \mathrm{trn})\}$. Frasa ini terbentuk dengan unsur pusat diisi oleh verba dan ditambah dengan verba intransitif. Penggabungan ketua unsur tersebut membentuk frasa verbal bahasa Banjar Hulu dengan struktur unsur pengisi $\{\mathrm{V}+(\mathrm{V} ; \operatorname{trn})\}$.

Data 1

\begin{tabular}{|c|c|}
\hline Kalimat & $\begin{array}{l}\text { Mamak tulak manukar } \\
\text { wadai jah di kadai } \\
\text { (Ibu pergi membeli kue di } \\
\text { warung) }\end{array}$ \\
\hline Frasa verbal & tulak manukar \\
\hline Kata Tambah & Manukar \\
\hline Verba UP & tulak \\
\hline
\end{tabular}

Berdasarkan data di atas dapat diketahui terdapat frasa verbal tulak manukar yang terbentuk dari kata tulak (V) dan manukar (V.trn). Frasa tulak manukar dalam kalimat di atas mempunyai distribusi yang sama dengan kata tulak. Kata manukar termasuk golongan V (transitif). Oleh karena itu, frasa tulak manukarjuga termasuk golongan $\mathrm{V}$. Kata tulak termasuk golongan kata verba, sedangankan kata manukar termasuk golongan $\mathrm{V}$ (transitif) yang difungsikan sebagai atribut kata tulak. Jadi, secara kategorial frasa tersebut terdiri dari manukar (V) sebagai atribut, dan tulak (verba) sebagai UP yang tergolong sebagai frasa verbal dengan struktur $\mathrm{V}+$ (V;trn)

\section{b. Frasa Verbal $\{\mathbf{V}+\mathbf{A j k}\}$}

Frasa verbal bahasa Banjar Hulu ditemukan struktur frasa verbal $\{\mathrm{V}+\mathrm{Ajk}\}$ Frasa ini terbentuk dengan unsur pusat diisi oleh verba dan ditambah dengan ajektiva. Penggabungan ketua unsur tersebut membentuk frasa verbal bahasa Banjar Hulu dengan struktur unsur pengisi $\{\mathrm{V}+\mathrm{Ajk}\}$.

Data 2

Kalimat Urang tu bukah singancapan yat maapa lih? (dia itu berlari cepat lihat saja yang terjadi?)

Frasa verbal bukah singancapan

Kata tambah singancapan

Verba (UP) bukah

Berdasarkan data di atas dapat diketahui terdapat frasa verbal bukah singancapan yang terbentuk dari kata bukah (V) dan singancapan (Ajektiva). Frasa bukah singancapan dalam kalimat di atas mempunyai distribusi yang sama kata bukah (V). Kata bukah termasuk golongan verba yang menjadi unsur pusat. Selanjutnya, penanda frasa ini adalah frasa ferbal terdapatnya kata tambah singancapan tergolong kata ajektiva. Kata singancapan digunakan dalam frasa verbal tersebut menandakan hubungan distribusi yang sama dengan unsur pusat frasa verbalnya. Oleh karena itu, frasa bukah singancapan juga termasuk golongan frasa verbal. Kata bukah termasuk golongan kata verba, sedangankan kata singancapan termasuk golongan kata tambah ajektiva yang difungsikan sebagai atribut penghubung unsur pusat. Jadi, secara kategorial frasa tersebut terdiri dari singancapan (tambah ajektiva) sebagai atribut, dan bukah (V) sebagai UP yang tergolong sebagai frasa verbal dengan struktur Verba + Ajektiva.

\section{c. Frasa Verbal $\{$ Adv + V $\}$}

Frasa verbal bahasa Banjar Hulu ditemukan struktur frasa verbal $\{\mathrm{Adv}+\mathrm{V}\}$ Frasa ini terbentuk dengan unsur pusat diisi oleh verba dan ditambah dengan adv. Penggabungan ketua unsur tersebut membentuk frasa verbal bahasa Banjar Hulu dengan struktur unsur pengisi $\{\mathrm{Adv}+\mathrm{V}\}$.

Data 3

$\begin{array}{ll}\text { Kalimat } & \begin{array}{l}\text { Inyak handak tulak janya } \\ \text { jah? } \\ \text { (dia akan pergi katanya?) }\end{array} \\ \text { Frasa verbal } & \text { handak tulak } \\ \text { Kata tambah } & \text { handak } \\ \text { Verba (UP) } & \text { tulak }\end{array}$

Berdasarkan data di atas dapat diketahui terdapat frasa verbal handak tulak yang terbentuk dari kata handak (Adv) dan tulak 
(Verba). Frasa handak tulak dalam kalimat di atas mempunyai distribusi yang sama kata tulak (V). Kata tulak termasuk golongan verba yang menjadi unsur pusat. Selanjutnya, penanda frasa ini adalah frasa verbal terdapatnya kata tambah handak tergolong kata adverbia. Kata handak digunakan dalam frasa verbal tersebut menandakan hubungan distribusi yang sama dengan unsur pusat frasa verbalnya. Oleh karena itu, frasa handak tulak juga termasuk golongan frasa verbal. Kata tulak termasuk golongan kata verba, sedangankan kata handak termasuk golongan kata tambah adverbia yang difungsikan sebagai atribut penghubung unsur pusat. Jadi, secara kategorial frasa tersebut terdiri dari handak (tambah adverbia) sebagai atribut, dan tulak $(V)$ sebagai UP yang tergolong sebagai frasa verbal dengan struktur Adverbia + Verba.

\section{d. Frasa Verbal $\{\mathrm{V}+$ Preposisi $\}$}

Frasa verbal bahasa Banjar Hulu ditemukan struktur frasa verbal $\{\mathrm{V}+$ Preposisi\} Frasa ini terbentuk dengan unsur pusat diisi oleh verba dan ditambah dengan preposisi. Penggabungan ketua unsur tersebut membentuk frasa verbal bahasa Banjar Hulu dengan struktur unsur pengisi $\{\mathrm{V}+$ Preposisi $\}$.

$\begin{array}{ll}\text { Data } 4 & \begin{array}{l}\text { Utuh tulak ka atas janya jah. } \\ \text { (Utuh pergi ke atas } \\ \text { Kalimat }\end{array} \\ \text { Frasa verbal } & \begin{array}{l}\text { tulak ka atas } \\ \text { ka atas }\end{array} \\ \begin{array}{l}\text { Kata tambah } \\ \text { Verba (UP) }\end{array} & \text { tulak }\end{array}$

Berdasarkan data di atas dapat diketahui terdapat frasa verbal tulak $k a$ atas yang terbentuk dari kata tulak (V) dan $k a$ atas (preposisi). Frasa tulak ka atas dalam kalimat di atas mempunyai distribusi yang sama kata tulak (V). Kata tulak termasuk golongan verba yang menjadi unsur pusat. Selanjutnya, penanda frasa ini adalah frasa verbal terdapatnya kata tambah $\mathrm{ka}$ atas tergolong kata preposisi. Kata $k a$ atas digunakan dalam frasa verbal tersebut menandakan hubungan distribusi yang sama dengan unsur pusat frasa verbalnya. Oleh karena itu, frasa tulak $k a$ atas juga termasuk golongan frasa verbal. Kata tulak termasuk golongan kata verba, sedangankan kata $\mathrm{ka}$ atas termasuk golongan kata tambah preposisi yang difungsikan sebagai atribut penghubung unsur pusat. Jadi, secara kategorial frasa tersebut terdiri dari $k a$ atas (tambah preposisi) sebagai atribut, dan tulak $(V)$ sebagai unsur pusat yang tergolong sebagai frasa verbal dengan struktur Verba + preposisi.

\section{e. Frasa Verbal $\{\mathbf{V} ;(\mathbf{b a}-+\mathrm{N})+$ pronomina $\}$}

Frasa verbal bahasa Banjar Hulu ditemukan struktur frasa verbal $\{\mathrm{V} ;(\mathrm{ba}-+\mathrm{N})+$ pronomina\}. Frasa ini terbentuk dengan unsur pusat diisi oleh verba (ba-+an) dan ditambah dengan pronomina. Penggabungan ketua unsur tersebut membentuk frasa verbal bahasa Banjar Hulu dengan struktur unsur pengisi $\{\mathrm{V} ;(\mathrm{ba}-+\mathrm{N})+$ pronomina $\}$.

\section{Data 5}

$\begin{array}{ll}\text { Kalimat } & \begin{array}{l}\text { taluk dah tuah } \\ \text { (sekarang dia beranak } \\ \text { tiga sudah.) }\end{array} \\ \text { Frasa verbal } & \text { baanak taluk } \\ \text { Kata tambah } & \text { taluk } \\ \text { Verba (UP) } & \text { baanak }\end{array}$

Berdasarkan data di atas dapat diketahui terdapat frasa verbal baanak taluk yang terbentuk dari kata baanak $(\mathrm{V}$; ba- $+\mathrm{N})$ dan taluk (pronomina). Frasa baanak taluk dalam kalimat di atas mempunyai distribusi yang sama kata baanak (V). Kata baanak termasuk golongan verba derivasi nomina yang menjadi unsur pusat. Selanjutnya, penanda frasa ini adalah frasa verbal terdapatnya kata tambah taluk tergolong kata pronomina. Kata taluk digunakan dalam frasa verbal tersebut menandakan hubungan distribusi yang sama dengan unsur pusat frasa verbalnya. Oleh karena itu, frasa baanak taluk juga termasuk golongan frasa verbal. Kata baanak termasuk golongan kata verba, sedangankan kata taluk termasuk golongan kata tambah pronomina yang difungsikan sebagai atribut penghubung unsur pusat. Jadi, secara kategorial frasa tersebut terdiri dari taluk (tambah pronomina) sebagai atribut, dan baanak $(\mathrm{V} ; \mathrm{ba}-+\mathrm{N})$ sebagai unsur pusat yang 
tergolong sebagai frasa verbal dengan struktur

Verba derivasi nomina + pronomina.

\section{f. Frasa Verbal $\{$ V; (ba- N) + A $\}$}

Frasa verbal bahasa Banjar Hulu ditemukan struktur frasa verbal $\{\mathrm{V}$; $($ ba- $\mathrm{N})+$ A\}. Frasa ini terbentuk dengan unsur pusat diisi oleh verba $($ ba- $+\mathrm{N})$ dan ditambah dengan ajektiva. Penggabungan ketua unsur tersebut membentuk frasa verbal bahasa Banjar Hulu dengan struktur unsur pengisi $\{\mathrm{V}$; (ba- $\mathrm{N})+$ A\}.

$\begin{array}{ll}\text { Data 6 } & \text { Udin babajuk hanyar } \\ \text { Kalimat } & \begin{array}{l}\text { lih. } \\ \text { (Udin berbaju baru ya.) }\end{array} \\ \text { Frasa verbal } & \text { Babajuk hanyar } \\ \text { Kata tambah } & \text { Hanyar } \\ \text { Verba (UP) } & \text { Babajuk }\end{array}$

Berdasarkan data di atas dapat diketahui terdapat frasa verbal babajuk hanyar yang terbentuk dari kata babajuk $(\mathrm{V}$; ba- $+\mathrm{N})$ dan hanyar (Ajk). Frasa babajuk hanyar dalam kalimat di atas mempunyai distribusi yang sama kata babajuk (V). Kata babajuk termasuk golongan verba yang menjadi unsur pusat. Selanjutnya, penanda frasa ini adalah frasa verbal terdapatnya kata tambah hanyar tergolong kata ajektiva. Kata hanyar digunakan dalam frasa verbal tersebut menandakan hubungan distribusi yang sama dengan unsur pusat frasa verbalnya. Oleh karena itu, frasa babajuk hanyar juga termasuk golongan frasa verbal. Kata babajuk termasuk golongan kata verba derivasi nomina (V;ba$+\mathrm{N})$, sedangankan kata hanyar termasuk golongan kata tambah ajektiva yang difungsikan sebagai atribut penghubung unsur pusat. Jadi, secara kategorial frasa tersebut terdiri dari hanyar (tambah ajektiva) sebagai atribut, dan babajuk $(\mathrm{V} ; \mathrm{ba}-+\mathrm{N})$ sebagai unsur pusat yang tergolong sebagai frasa verbal dengan struktur Verba derivasi nomina + ajektiva.

\section{g. Frasa Verbal $\{\mathrm{V} ;($ ba-kan $+\mathrm{N})+\mathrm{N}\}$}

Frasa verbal bahasa Banjar Hulu ditemukan struktur frasa verbal $\{\mathrm{V}$; (ba-kan + $\mathrm{N})+\mathrm{N}$ \}. Frasa ini terbentuk dengan unsur pusat diisi oleh verba (ba-kan) dan ditambah dengan nomina. Penggabungan ketua unsur tersebut membentuk frasa verbal bahasa Banjar Hulu dengan struktur unsur pengisi $\{\mathrm{V} ;($ ba-kan $+\mathrm{N})+\mathrm{N}\}$.

\section{Data 7}

Urang harat baajaskan

Kalimat (urang baik agama? ja lih.

Frasa verbal Baajaskan agama?

Kata tambah Agama?

Verba (UP) Baajaskan

Berdasarkan data di atas dapat diketahui terdapat frasa verbal baajaskan agama? yang terbentuk dari kata baajaskan $(\mathrm{V}$; ba-kan+N) dan agama? (N). Frasa baajaskan agama? dalam kalimat di atas mempunyai distribusi yang sama kata baajaskan (V). Kata baajaskan termasuk golongan verba derivasi nomina yang menjadi unsur pusat. Selanjutnya, penanda frasa ini adalah frasa verbal terdapatnya kata tambah agama? tergolong kata nomina. Kata agama? digunakan dalam frasa verbal tersebut menandakan hubungan distribusi yang sama dengan unsur pusat frasa verbalnya. Oleh karena itu, frasa baajaskan agama? juga termasuk golongan frasa verbal. Kata baajaskan termasuk golongan kata verba derivasi nomina $(\mathrm{V} ; \mathrm{ba}-+\mathrm{N})$, sedangankan kata agama? termasuk golongan kata tambah nomina yang difungsikan sebagai atribut penghubung unsur pusat. Jadi, secara kategorial frasa tersebut terdiri dari agama? (tambah nomina) sebagai atribut, dan baajaskan $(\mathrm{V} ; \mathrm{ba}-+\mathrm{N})$ sebagai unsur pusat yang tergolong sebagai frasa verbal dengan struktur Verba derivasi nomina + nomina.

\section{SIMPULAN}

Berdasarkan hasil penelitian yang telah dinyatakan pada bagian sebelumnya, dapat disimpulkan bahwa struktur frasa verbal bahasa Banjar Hulu ditemukan beberapa struktur frasa yang bervariasi ditinjau berdasarkan kelas kata pembentuk frasa verbal bahasa Banjar Hulu dan berdasarkan fungsi unsur pembentuk frasa verbal bahasa Banjar Hulu. Pertama struktur frasa verbal berdasarkan kelas katanya; (a) Frasa 
Verbal $\{\mathrm{V}+(\mathrm{V} ; \mathrm{trn})\}$, (b) Frasa Verbal $\{\mathrm{V}+$ Ajk\}, (c) Frasa Verbal $\{\mathrm{Adv}+\mathrm{V}\}$, (d) Frasa Verbal $\{\mathrm{V}+$ Preposisi $\}$, (e) Frasa Verbal $\{\mathrm{V} ;(\mathrm{ba}-+\mathrm{N})+$ pronomina $\}$, (f) Frasa Verbal $\{\mathrm{V} ;($ ba- N) $+\mathrm{A}\}$, (g) Frasa Verbal $\{\mathrm{V}$; (ba-kan $+\mathrm{N})+\mathrm{N}\}$. Kedua struktur frasa verbal berdasarkan fungsi unsur pembentuk, yakni meliputi (a) Frasa Verbal Koordinatif, (b) Frasa Verba Modifikatif, (c) Frasa Verba Apositif. Ditinjau berdasarkan fungsi unsur pembentukan frasa verbal bahasa Banjar Hulu juga ditemukan frasa verbal koordinatif, yakni frasa verbal yang kedua unsurnya memiliki hubungan kesetaraan. Selanjutnya, ditemukan juga frasa verbal modikatif, yakni frasa yang ditinjau dari pengisian pewatas dalam unsur pusat baik pewatas depan atau belakang. Pewatas yang dimaksud di sini adalah aspektualitas, modalitas, dan temporalitas. Selain itu, bahasa Banjar Hulu juga memiliki frasa verbal apositif, yakni frasa yang ditinjau berdasarkan terdapatnya unsur yang ditempatkan sebagai keterangan tambahan atau selipan penjelasan dalam unsur pusat.

\section{REFERENSI}

Arikunto, Suharsimi (1993). Prosedur Penelitian Ilmiah, Suatu Pendekatan Praktik. Jakarta: Rineka Cipta.

Asnawi. (2014). Komposisi Nominal Bahasa Banjar Hulu. Jurnal Geram (Gerakan Aktif Menulis), 4(1), 21-33.

Asnawi. (2015). Reduplikasi Verba Denomina Bahasa Banjar Hulu: Tinjauan Bentuk dan Semantik Gramatikal. Jurnal Geram (Gerakan Aktif Menulis), 8(1), 54-67.

Asnawi. (2017). Afiks Pembentuk Reduplikasi Nominal Bahasa Banjar Hulu: Tinjauan Bentuk Gramatikal. Jurnal Geram (Gerakan Aktif Menulis), 5(1), 33-42.

Hapip, Abdul Djebar. (1977). Kamus Bahasa Banjar-Indonesia. Jakarta: Pusat Pembinaan dan Pengembangan Bahasa Depertemen Pendidikan dan Kebudayaan.

Mahdini. (2003). Sastra Lisan Masyarakat Melayu Banjar Indragiri Hilir. Pekanbaru: Daulat Riau.

Mahsun. (2006). Metode Penelitian Bahasa: Tahapan Strategi, Metode, dan Tekniknya. Jakarta: Raja Grafindo Persada.
Ramlan, M. (2005). Ilmu Bahasa Indonesia Morfologi Suatau Tinjauan Deskriptik. Yogyakarta : CV. Karyono.

Suryadikara, Fudiat dkk. (1981). Geografi Dialek Bahasa Banjar Hulu. Jakarta: Pusat Pembinaan dan Pengembangan Bahasa Depertemen Pendidikan dan Kebudayaan.

Sudaryanto. (1993). Metode dan Aneka Teknik Analisis Bahasa: Pengantar Penelitian Wahana Kebudayaan secara Linguistik. Yogyakarta: Duta Wacana Universty Press. 